\title{
CONSTRUÇÃO DE UM MODELO DE MATURIDADE NO MERCADO DE CAFÉS SUSTENTÁVEIS
}

\author{
Geraldo Magela Jardim Barra \\ Doutor em Administração \\ Rede de Ensino Doctum \\ Juiz de Fora - Minas Gerais - Brasil \\ gmjbar@yahoo.com.br \\ Marcelo Bronzo Ladeira \\ Doutor em Administração \\ Universidade Federal de Minas Gerais \\ Belo Horizonte - Minas Gerais - Brasil \\ marcelobronzo@face.ufmg.br
}

\section{RESUMO}

Este artigo tem como objetivo a construção de um modelo de maturidade para processos certificados no mercado de cafés sustentáveis. A hipótese deste trabalho é a de que o nível de maturidade dos processos certificados está, positiva e fortemente, associado ao desempenho dessas organizações. Essa hipótese está relacionada ao campo de estudos de modelos de maturidade de processos. O modelo de maturidade foi construído sob a ótica da produção sustentável, tendo como base o código de conduta UTZ Certified. Após a sua elaboração, o modelo de maturidade foi validado por especialistas por meio do método do grupo focal. Em seguida, o questionário do modelo de maturidade foi aplicado por meio de um survey aos cafeicultores brasileiros que foram certificados pela UTZ. Os resultados da pesquisa evidenciaram que os cafeicultores que obtiveram o maior nível de maturidade de processos tendem a apresentar um melhor desempenho financeiro e mercadológico. Além disso, os resultados da pesquisa indicam que os cafeicultores com os maiores tempos de certificação apresentaram os maiores níveis de maturidade. Acredita-se que o modelo de maturidade proposto é uma ferramenta importante para gestão de processos no mercado de cafés sustentáveis, pois permitirá avaliar, em pesquisas futuras, a maturidade dos processos dos cafeicultores certificados.

Palavras-chave: Cafés sustentáveis; Certificação; Modelo de maturidade; Sustentabilidade.

\section{CONSTRUCTION OF A MATURITY MODEL IN THE SUSTAINABLE COFFEE MARKET}

\begin{abstract}
This article aims to build a maturity model for certified processes in the sustainable coffee markets. The hypothesis of this research, related to process maturity models field, is that the level of maturity of the certified processes is positively and strongly associated to the performance of the organizations. The maturity model was built from the point of view of sustainable production based on the UTZ Certified Code of Conduct. The maturity model was validated by specialists through the focal group method. Then, the questionnaire of the maturity model was applied through a survey to Brazilian coffee growers who were certified by UTZ. The results showed that coffee growers who obtained the highest level of process maturity tend to present stronger financial and marketing performance. In addition, the results indicate that coffee growers with the highest certification times presented the highest levels of maturity. We believe that the proposed maturity model is an important tool for the management of processes in the sustainable coffee market, as it may allow evaluating the maturity of certified coffee growers' processes.
\end{abstract}

Key words: Certification; Maturity model; Sustainability; Sustainable coffee.

Revista de Gestão Social e Ambiental - RGSA, São Paulo, v. 12, n. 1, p. 89-107, jan./abr. 2018. 


\section{INTRODUÇÃO}

A comercialização de cafés sustentáveis no mundo cresceu muito desde 2000, definindo um atrativo mercado para cafés sustentáveis, no qual o Brasil se destaca como sendo um dos maiores exportadores nesse mercado (Potts et al., 2014). De fato, o mercado de cafés sustentáveis tornou-se uma oportunidade de negócios. Todavia, há que ressaltar as dificuldades de comercialização nesse mercado, tais como desenvolvimento de relacionamentos baseados em confiança, implementação de mecanismos sinalizadores de qualidade (selos, certificados, rastreabilidade) e o desenvolvimento de sistemas de produção sustentáveis.

Há desde o início dos anos 2000 uma profusão de tipos de certificação no mercado de cafés sustentáveis. Esses certificados coexistem e competem entre si, dificultando a diferenciação entre o papel de cada certificação nesse mercado (Reinecke et al, 2012; Panhuysen e Pierrot, 2014). Dentre os diversos tipos de certificados aceitos no mercado do café, merece destaque a certificação UTZ pela sua abordagem centrada no conceito de sustentabilidade.

O UTZ Certified é um programa de certificação que demonstra uma vocação para prover um sistema de coordenação do sistema agroindustrial (SAG) do café, pois desenvolveu iniciativas que foram importantes para coordenação desse sistema de produção (Leme, 2015). A UTZ é um dos maiores programas para agricultura sustentável, englobando a certificação de café que tem sido um condutor basilar do desenvolvimento de melhores práticas de gestão dos processos das firmas envolvidas na produção e comercialização de café sustentável no Brasil, tendo o seu código de conduta centrado no conceito de boas práticas agrícolas e boas práticas de gestão.

Isto posto, entende-se que a possibilidade de desenvolvimento de um modelo de maturidade em processos certificados no setor de cafés sustentáveis baseado nesta certificação pode ser uma iniciativa relevante para a produção de café sustentável. Neste trabalho, acredita-se na premissa de que a certificação de processos favorece a firma a percorrer processos evolutivos influenciando em ganhos de desempenho, uma vez que a certificação é um instrumento de difusão e institucionalização das melhores práticas produtivas.

A certificação é um investimento importante para atuar no mercado de cafés sustentáveis, pois se trata de um mecanismo sinalizador de qualidade que diminui os custos de transação e reduz a assimetria de informação existente entre o comprador e vendedor. A implementação desse mecanismo sinalizador de qualidade no mercado do café começa a se tornar uma tendência, pois a melhoria da qualidade dos cafés não é, por si só, capaz de possibilitar a comercialização em mercados de produtos diferenciados, já que o certificado é cada vez mais exigido em toda extensão da cadeia produtiva do café.

Embora a certificação favoreça a geração de negócios em mercados que permitem a obtenção de preço prêmio, é importante verificar se a certificação tem a capacidade de levar as firmas a percorrerem processos evolutivos, verificados pela maturação e pelo desempenho das firmas no tempo. De fato, podem existir situações em que a certificação não seja capaz de promover a maturidade nem maior desempenho às empresas certificadas.

É importante destacar que no campo do conhecimento de maturidade de processos, ainda não há uma teoria estabelecida de que as empresas já certificadas com o tempo tendem a se tornar mais evoluídas pela maturação dos seus processos. Além do mais, também ainda não existe uma teoria solidificada que sustente a relação entre níveis de maturidade de processos certificados e desempenho organizacional. Sendo assim, pela necessidade de analisar se a certificação é efetiva no seu papel de condutora da maturidade dos processos certificados das firmas nos sistemas agroindustriais (SAGs) é que foi desenvolvido este trabalho.

Nessa linha de raciocínio e baseando-se na premissa de que a certificação de processos favorece a firma a percorrer processos evolutivos influenciando em ganhos de desempenho, neste trabalho, formulou-se seguinte problema de pesquisa: quais são os efeitos da maturidade de processos certificados em SAGs sobre o desempenho competitivo das firmas certificadas?

Revista de Gestão Social e Ambiental - RGSA, São Paulo, v. 12, n. 1, p. 89-107, jan./abr. 2018. 
Com este estudo, buscou-se ampliar as concepções acerca da visão das empresas certificadas sobre a certificação UTZ que poderão ser norteadoras para o agronegócio no Brasil. É, portanto, a partir da concepção de que as certificações precisam ser eficientes no suporte aos negócios das empresas certificadas que se estabeleceu o interesse deste trabalho.

Assim, com a finalidade de desdobrar os argumentos precedentes, este trabalho teve como objetivo desenvolver e validar um modelo de maturidade para processos certificados para que a relação entre maturidade dos processos das firmas certificadas e o seu impacto no desempenho mercadológico e financeiro das firmas pudesse ser avaliado.

Trata-se de um estudo descritivo-conclusivo no mercado de cafés sustentáveis. Para isso, após uma extensa pesquisa sobre maturidade de processos e certificações na cafeicultura, o modelo de maturidade foi desenvolvido com base no código de conduta UTZ Certified (2015) e, em seguida, validado por especialistas e aplicado aos cafeicultores certificados pela UTZ por meio de um survey.

Nesta seção introdutória, abordou-se o problema de pesquisa, o objetivo e a justificativa. $\mathrm{Na}$ segunda seção, sistematizou-se o marco conceitual do artigo. No seu início, foram apresentados os temas certificação na cafeicultura brasileira, sistemas de medição de desempenho e maturidade de processos. Nesta seção, tem-se a proposta a contribuição desta pesquisa: Modelo de Maturidade para Processos Certificados em SAG. Na terceira seção, os processos metodológicos do trabalho foram descritos, abordando-se as fases exploratória e conclusiva da pesquisa. Na quarta seção, foram apresentados os resultados da pesquisa. Nesta seção, foi realizada a análise da influência dos níveis de maturidade sobre o desempenho das firmas pesquisadas. Na quinta seção, foram apresentadas as discussões sobre os resultados das fases exploratória e conclusiva. Por fim, na seção final, tem-se a descrição das considerações finais do trabalho.

\section{REFERENCIAL TEÓRICO}

\subsection{Certificação na Cafeicultura Brasileira}

Com a desregulamentação do mercado cafeeiro na década de 1990 do século XX, houve a criação de uma nova conjuntura, no qual a exigência por produtos certificados no mercado mundial passou a ser um fator fundamental para a competição. Nesse cenário, foi necessária a adequação dos processos aos códigos de conduta voluntários das certificadoras. Nesse mercado, existem vários sistemas de certificação que se complementam ou concorrem entre si. Dentre estes, merecem destaque os sistemas de certificação realizados por meio independente de monitoramento e acreditação (terceira parte) e os sistemas de verificação. No primeiro grupo, destacam-se: Fairtrade Labelling Organizations (FLO é o órgão normatizador), a Certificação Orgânica (Ifoam - Federação Internacional de Movimentos de Agricultura Orgânica - é o órgão normatizador), a Rainforest Alliance (RAS - Rede de Agricultura Sustentável é o órgão normatizador) e o UTZ Certified (UTZ é o órgão normatizador). Há três sistemas de verificação: a Starbucks tem o seu próprio padrão, denominado Starbucks' Coffee and Farmer Equity Practices (C.A.F.E. Practices); o sistema Triple AAA da Nespresso; o Código Comum da Comunidade Cafeeira (4C) (Leme, 2015).

Com relação a certificação de café, diversos estudos foram realizados no Brasil de forma continuada. No entanto, ainda não foi realizada uma pesquisa sobre a relação entre certificação e maturidade de processos. Barra (2006) analisou a relação da certificação Bsca com o desempenho. A certificação UTZ foi estudada por Martinez (2006) e Leme (2015.); a certificação de origem da Federação do Cafeicultores do Cerrado - FCC foi estudada por Mafra (2008). Palmieri (2008) estudou os impactos socioambientais da certificação Rainforest Alliance em fazendas produtoras de café. A certificação Fair Trade na cafeicultura foi estudada por Pedini (2011), Miranda e Saes (2012) e Souza et al., 2015. As boas práticas agrícolas e certificação na cafeicultura foram estudadas por Pereira (2013), Rosa (2014 e Prado (2014).

Revista de Gestão Social e Ambiental - RGSA, São Paulo, v. 12, n. 1, p. 89-107, jan./abr. 2018. 
Na década de 1990, tem-se o início das atividades das diferentes certificações no Brasil, com a certificação orgânica na década de 1990 e pelo fair trade em 1997. Posteriormente, na década seguinte, a busca pela implementação das certificações UTZ e Rainforest Alliance. Nesta década, é importante destacar a fundação da UTZ no ano de 1997 por cafeicultores guatemaltecos e a torrefadora europeia Ahold Coffee Company (Leme, 2015).

$\mathrm{Na}$ década de 2000, tem-se o início das atividades das diferentes certificações no Brasil, como a UTZ e a Rainforest Alliance em 2002, o início do programa 4C nos anos 2000 e a criação pelo governo de Minas Gerais do programa Certifica Minas Café no ano de 2006 (Leme, 2015).

$\mathrm{Na}$ esfera governamental, merecem destaques no Brasil os esforços que deram prosseguimento ao "Certicafé". Inicialmente, o projeto "Agrominas", que foi criado em 2004 com foco no aprimoramento da base da cadeia do café. Posteriormente, o projeto "Certifica Minas", que foi criado a partir de 2008 objetivando a certificação de "boas práticas de produção", incorporando o fator sustentabilidade (Dutra, 2009).

A partir de 2006, o foco nas práticas de gestão dentro das lavouras e na da cadeia de custódia por meio dos sistemas UTZ passa a ter reflexo do Código de Conduta, nas empresas compradoras. A UTZ começa a demonstrar sua vocação para prover sistemas de rastreabilidade, controle e coordenação de cadeias de produtos certificados. Nos anos de 2005 e 2006, a UTZ se empenhou em criar o "Portal dos Membros", que foi um sistema de controle que, posteriormente, originaria um sistema de rastreabilidade (Octopus) e, mais adiante, um portal (Good Inside Portal GIP). Essas iniciativas foram importantes para coordenação de SAGs sendo realizada por meio da criação de softwares on-line para o controle de seus sistemas de certificação, rastreabilidade e vendas (Leme, 2015).

Em 2010, o Sistema Octopus criado pela UTZ alavancou as transações de café e a verificação do pagamento de prêmio. Em 2011, o sistema sofreu uma grande modificação e passou a ser conhecido como Good Inside Portal. O GIP é um sistema de gestão da certificação que congrega as principais atividades dos agentes ligados a UTZ. Os cafeicultores e compradores, ao acessar o portal eletrônico GIP, têm acesso a uma plataforma de negociação que contribui para formar arranjos de precificação e encontros de mercado com ferramentas de transação (Leme, 2015).

\subsection{Sistema de medição de desempenho}

Desde o uso do tableau de bord no início do século XX, as metodologias de avaliação de desempenho têm evoluído significativamente tanto no meio acadêmico quanto no empresarial, merecendo destaque o Balanced Scorecard (BSC). De fato, Nelly (2005), analisando as publicações no período compreendido entre 1995 a 2004 sobre medição de desempenho, demonstra que Kaplan e Norton (1997) foram os autores mais citados em 8 dos 10 anos pesquisados.

É importante destacar que o BSC, além de ser tema preferencial nas pesquisas acadêmicas relacionadas a sistema de desempenho organizacional, tem sido priorizado nas escolhas dos gestores para desenvolvimento estratégico e medição de desempenho, sendo muito utilizado no mundo.

Inicialmente, Kaplan e Norton (1997), ao desenvolverem o BSC, o definiram como sendo um sistema de mensuração de desempenho. No entanto, com o passar do tempo, pela sua maturação conceitual, o BSC foi definido como um sistema de gestão estratégica (Kaplan e Norton, 1997).

O BSC pode ser considerado um sistema mais amplo para avaliação do desempenho empresarial, dado que parte do estabelecimento de indicadores e metas relacionadas às diretrizes e estratégias é definido pelos gestores em um sistema de gestão estratégica.

Kaplan e Norton (1997) criaram o BSC no início da década de 1990, definindo-o como um meio de traduzir a missão e a estratégia em objetivos e medidas, promovendo a comunicação, a informação e o aprendizado. De fato, o seu diferencial em relação aos outros métodos é sua derivação da missão e da estratégia da empresa, não sendo apenas um método de controle de

Revista de Gestão Social e Ambiental - RGSA, São Paulo, v. 12, n. 1, p. 89-107, jan./abr. 2018. 
desempenho, mas também um sistema de comunicação da estratégia e de aprendizado (Kaplan e Norton, 1997).

As ideias do BSC surgiram quando Kaplan e Norton (1997) perceberam que o frequente uso de medidas financeiras baseadas em parâmetros contábeis apresentava limitações. Para esses autores, os dados contábeis refletem muito bem o passado da organização, mas podem ser limitados para previsões de cenários futuros, podendo ser considerados indicadores inadequados do valor econômico de uma organização.

Com o BSC, os gestores passam a tomar as suas decisões baseadas na conjugação de indicadores financeiros e não financeiros de curto e longo prazo, sintetizado nas suas quatro perspectivas equilibradas: financeira, clientes, processos internos, aprendizagem e crescimento. O BSC pode ser considerado um sistema mais amplo para avaliação do desempenho empresarial, dado que parte do estabelecimento de indicadores e metas está relacionada às diretrizes e estratégias definidas pelos gestores. O BSC traduz a missão e a estratégia das empresas em um conjunto abrangente de medidas de desempenho que serve de base para um sistema de medição e gestão estratégica. Por meio de um conjunto articulado de objetivos, metas, vetores de desempenho que se articulam em uma relação de causa e efeito, o desempenho organizacional é medido por meio de suas quatro perspectivas (Kaplan e Norton, 1997).

Destaca-se que essas quatro perspectivas do BSC equilibram os objetivos de curto e longo prazos, os resultados desejados e os vetores desses resultados, as medidas concretas e mais subjetivas. Grosso modo, no BSC há a pressuposição de que os indicadores financeiros, por si só, não são suficientes para contemplar aspectos relevantes que impulsionam a rentabilidade no longo prazo. Enquanto o vetor de curto prazo é definido por medidas financeiras, os vetores de longo prazo são definidos por medidas de longo prazo (Kaplan e Norton, 1997).

$\mathrm{Na}$ perspectiva do BSC, as estratégias podem ser estruturadas em uma relação de causa e efeito entre variáveis. A vantagem desta estruturação é a facilidade da sua elaboração e da própria comunicação. O diferencial do BSC é o uso dos mapas estratégicos, que são ferramentas interessantes de comunicação da estratégia dentro da organização. A arquitetura de relações lógicas do mapa estratégico permite a comunicação dos objetivos estratégicos a todos os colaboradores, bem como a sua relação de causa e efeito, o que contribui para um alinhamento estratégico (Kaplan e Norton, 1997).

Por fim, assume-se que o desempenho deve ser avaliado por meio da combinação de diferentes indicadores. Neste trabalho, as perspectivas mercadológicas e financeiras do BSC foram selecionadas em função dos objetivos precípuos deste trabalho de pesquisa, sendo estas as principais demandas para certificação (ampliar mercado e lucratividade) ${ }^{1}$.

\subsection{Modelo de maturidade para processos certificados}

O modelo de Crosby (1979) "Grid de Maturidade em Gerência da Qualidade" foi predecessor dos modelos de maturidade. Por seu caráter seminal, este modelo de maturidade influenciou, posteriormente, a construção de outros modelos de maturidade, tal como o Capability Maturity Model (CMM), desenvolvido pelo Instituto de Engenharia de Software (SEI) em 1983. Uma série de modelos maturidade direcionados a várias áreas foi elaborada a partir do CMM (Oliveira, 2009).

Nesta pesquisa, foram escolhidas as premissas dos modelos de maturidade "Process and Enterprise Maturity Model" (Pemm) de Hammer (2007), e "Supply Chain Maturity Model" (SCMM) de Mccormack et al. (2003). Para analisar a relação da maturidade com desempenho, escolheram-se as premissas de mensuração de desempenho do Balanced Scorecard (BSC) de Kaplan e Norton (1997).

O modelo de maturidade Pemm foi desenvolvido por Hammer (2007) com o intuito de responder a demanda empresarial por gestão de processos. O Pemm foi testado e validado por um conjunto de empresas vinculadas ao "Phoenix Consortium" nos Estados Unidos. Por sua vez, o

Revista de Gestão Social e Ambiental - RGSA, São Paulo, v. 12, n. 1, p. 89-107, jan./abr. 2018. 
SCMM foi construído por Mccormack et al. (2003) fundamentado nos conceitos de maturidade de processos sob inspiração do CMM. Este modelo de maturidade permite aos gestores identificar áreas de progresso e estagnação nas firmas na ótica do Supply Chain Management. Pelas concepções do Pemm e do Scmm, quanto maior o nível de maturidade, maior a excelência dos processos e, por extensão, maior será o desempenho organizacional.

No geral, os modelos de maturidade são compostos por cinco níveis evolutivos. O quinto nível denota um estado de otimização, no qual traduz a preocupação central de maximização de desempenho dos modelos de maturidade. A relação entre maturidade e desempenho está presente nos modelos de maturidade (MCcormack et al., 2003; Oliveira, 2009, Bronzo et al., 2013).

Em geral, nos modelos de maturidade, há uma concepção de melhoria contínua baseada em mudanças incrementais e não em transformações radicais dos processos, característica já presente no momento precursor de Crosby (1979). Nesta linha de raciocínio, a concepção básica é que o amadurecimento de processos perpassa por etapas de evolução que se desenvolvem a partir de um estágio inicial até um estágio final, em que há a combinação de elementos evolucionários oriundos da adoção de melhores práticas (Lahti et al., 2009).

A hipótese deste trabalho é a de que o nível de maturidade dos processos certificados está positivo e fortemente associado ao desempenho dessas organizações. Essa hipótese está relacionada ao campo de estudos de modelos de maturidade de processos (Bronzo et al., 2013; MCcormack et al., 2007; MCCormack et al., 2011; Oliveira et al., 2007; Oliveira, 2009; Oliveira et al., 2011; Trkman et al., 2011; Trkman et al., 2012 ; Souza et al, 2015)

\subsubsection{Construção do modelo de maturidade}

A construção do modelo de maturidade iniciou-se pelo desenvolvimento dos estágios de maturidade. As variáveis que constituem do modelo foram especificadas a partir dos atributos relevantes ao processo de acreditação desenvolvido pela UTZ Certified (2015). Os atributos foram distribuídos em níveis de maturidade, seguindo-se aqui os níveis afins ao Modelo de Maturidade para Processos Certificados em SAG apresentados na figura 1.

Para cada um dos atributos, em cada nível de maturidade, foram desenvolvidos cinco indicadores, que permitiram definir os escores das firmas. Os atributos foram agrupados por componentes avaliados pelos níveis de maturidade. Os indicadores foram mensurados por meio de questões estruturadas numa escala de cinco pontos, variando de 1 ponto (nível adhoc) até 5 pontos (nível otimizado) - (figura 2).

\begin{tabular}{|c|c|}
\hline Nível & Definição \\
\hline Adhoc & $\begin{array}{l}\text { 1. O sistema de gestão ainda não inclui a documentação de processos } \\
\text { 2. Não há mensuração do desempenho dos processos } \\
\text { 3. Não há rastreabilidade do produto no processo } \\
\text { 4. Não há a aplicação de BPA no processo de lavoura } \\
\text { 5. Não há a aplicação de BPA no processamento } \\
\text { 6. Não há práticas de sustentabilidade }\end{array}$ \\
\hline $\begin{array}{l}\text { Iniciad } \\
\mathrm{o}\end{array}$ & $\begin{array}{l}\text { 1. O sistema de gestão não está suficientemente estruturado em relação a documentação de processos } \\
\text { 2. As métricas de desempenho dos processos não estão suficientemente estruturadas } \\
\text { 3. A rastreabilidade do produto no processo não está suficientemente estruturada } \\
\text { 4. A aplicação de BPA no processo de lavoura não está suficientemente estruturada } \\
\text { 5.A aplicação de BPA no processamento não está suficientemente estruturada } \\
\text { 6. A aplicação das práticas de sustentabilidade não está suficientemente estruturada }\end{array}$ \\
\hline $\begin{array}{l}\text { Definid } \\
\mathrm{o}\end{array}$ & $\begin{array}{l}\text { 1. O sistema de gestão define, de forma relativamente estruturada, a documentação de processos } \\
\text { 2. As métricas de desempenho dos processos estão relativamente estruturadas } \\
\text { 3. A rastreabilidade do produto no processo está relativamente estruturada } \\
\text { 4. A aplicação de BPA no processo de lavoura está relativamente estruturada } \\
\text { 5.A aplicação de BPA no processamento está relativamente estruturada } \\
\text { 6. A aplicação das práticas de sustentabilidade está relativamente estruturada }\end{array}$ \\
\hline & 1. O sistema de gestão define, de forma devidamente estruturada, a documentação de processos \\
\hline
\end{tabular}

Revista de Gestão Social e Ambiental - RGSA, São Paulo, v. 12, n. 1, p. 89-107, jan./abr. 2018. 


\begin{tabular}{|l|l|}
\hline \multirow{2}{*}{$\begin{array}{l}\text { Estrutu } \\
\text { rado }\end{array}$} & $\begin{array}{l}\text { 2. As métricas de desempenho dos processos estão devidamente estruturadas } \\
\text { 3. A rastreabilidade do produto no processo está devidamente estruturada } \\
\text { 4. A aplicação de BPA no processo de lavoura está devidamente estruturada } \\
\text { 5. A aplicação de BPA no processamento está devidamente estruturada } \\
\text { 6. A aplicação das práticas de sustentabilidade está devidamente estruturada }\end{array}$ \\
\hline $\begin{array}{l}\text { 1. O sistema de gestão define de forma devidamente estruturada a documentação de processos } \\
\text { beneficiando sua gestão }\end{array}$ \\
$\begin{array}{l}\text { 2. As métricas de desempenho dos processos estão devidamente estruturadas beneficiando sua gestão } \\
\text { 3. A rastreabilidade do produto no processo está devidamente estruturada beneficiando sua gestão } \\
\text { 4. A aplicação de BPA no processo de lavoura está devidamente estruturada beneficiando sua gestão } \\
\text { ado }\end{array}$ \\
$\begin{array}{l}\text { 5. A aplicação de BPA no processamento está devidamente estruturada beneficiando sua gestão } \\
\text { 6. A aplicação das práticas de sustentabilidade está devidamente estruturada beneficiando sua gestão }\end{array}$ \\
\hline
\end{tabular}

Figura 1: Modelo de maturidade para processos certificados em SAG (Mmsag)

Fonte: Barra (2016, p. 69)

O construto "Documentação de processos" é composto por cinco indicadores $\left(\mathrm{I}_{1}+\mathrm{I}_{2}+\mathrm{I}_{3}+\mathrm{I} 4+\mathrm{I}\right.$ ). Cada Indicador é possível de obter valores de 1 a 5 (Adhoc-1, Iniciado-2, Definido-3, Estruturado-4, Otimizado-5). Assim, a firma avaliada poderá obter, no mínimo, cinco pontos no construto "Documentação de processos" e, no máximo, 25 pontos neste construto. Já a figura 3 apresenta os construtos e os indicadores da variável latente "Desempenho".

\begin{tabular}{|c|c|}
\hline Domínio do construto & Indicadores \\
\hline $\begin{array}{l}\text { Documentação dos processos: } \\
\text { Compreende uma clara definição, } \\
\text { compreensão e documentação do que } \\
\text { devem ser feitas em um processo de } \\
\text { negócios (Lockamy; MCCormack, } \\
\text { 2004). }\end{array}$ & $\begin{array}{l}\text {-Documentação que define o pessoal responsável pela monitoração e } \\
\text { controle do processo } \\
\text {-Documentação do fluxo dos processos } \\
\text {-Documentação de dados de produção (mapas, área de produção, } \\
\text { estimativa de produção e etc.) } \\
\text {-Gerenciamento de riscos e o plano de gestão } \\
\text {-Manutenção de registros/controle das operações de campo }\end{array}$ \\
\hline $\begin{array}{l}\text { Medição dos processos: } \\
\text { Compreende a medição de aspectos } \\
\text { do processo como qualidade, tempo } \\
\text { de ciclo, custo do processo e } \\
\text { variabilidade (MCCormack et al., } \\
\text { 2003). }\end{array}$ & $\begin{array}{l}\text {-Indicadores de desempenho relacionados à produtividade } \\
\text {-Indicadores de otimização do rendimento e eficiência agrícola } \\
\text {-Metas de desempenho de melhoria contínua } \\
\text {-Autoavaliação dos processos em relação ao código de conduta no } \\
\text { UTZ Certified } \\
\text {-Indicadores de controle de qualidade do processo/produto }\end{array}$ \\
\hline $\begin{array}{l}\text { Rastreabilidade no processo: } \\
\text { "Garantia de que os produtos } \\
\text { sustentáveis certificados são } \\
\text { originários de uma fonte certificada } \\
\text { e/ou asseguram uma produção } \\
\text { sustentável, por meio de um sistema } \\
\text { de identificação registrado" (UTZ } \\
\text { Certified, 2015, p. 11). }\end{array}$ & $\begin{array}{l}\text {-Disponibilidade de informação sobre insumos } \\
\text {-Disponibilidade de informação sobre café em pós-colheita } \\
\text {-Disponibilidade de informação sobre café beneficiado } \\
\text {-Capacidade de identificar o café durante o processo } \\
\text {-Manutenção de registros e faturas para garantir a rastreabilidade }\end{array}$ \\
\hline $\begin{array}{l}\text { BPA de Lavoura: } \\
\text { "Práticas que abordam a } \\
\text { sustentabilidade ambiental, econômica } \\
\text { e social para processos na exploração } \\
\text { agrícola e pós-produção que resultam } \\
\text { em produtos agrícolas seguros e de } \\
\text { qualidade" (UTZ Certified, 2015, p. } \\
\text { 9). }\end{array}$ & $\begin{array}{l}\text { - BPA de plantio } \\
\text { - BPA de manutenção da propriedade } \\
\text { - BPA de gestão do solo e fertilidade } \\
\text { - BPA de manejo de pragas e doenças } \\
\text { - BPA de uso de pesticidas e fertilizantes }\end{array}$ \\
\hline $\begin{array}{l}\text { BPA de Processamento: } \\
\text { "Transformação dos produtos } \\
\text { colhidos em produtos acabados ou } \\
\text { inacabados, incluindo a alteração de } \\
\text { produtos primários (matérias) na } \\
\text { fazenda (UTZ Certified, 2015, p. 11). }\end{array}$ & $\begin{array}{l}\text { - BPA de colheita definidos no UTZ Certified } \\
\text { - BPA de secagem de café definidos no UTZ Certified. } \\
\text { - BPA de lavagem de café definidos no UTZ Certified } \\
\text { - BPA de armazenamento de café (tulhas) definidos no UTZ Certified } \\
\text { - BPA de benefício definido no UTZ Certified }\end{array}$ \\
\hline Sustentabilidade de Processos: & -Uso sustentável da água definidos no UTZ Certified \\
\hline
\end{tabular}

Revista de Gestão Social e Ambiental - RGSA, São Paulo, v. 12, n. 1, p. 89-107, jan./abr. 2018. 


\begin{tabular}{|c|c|}
\hline $\begin{array}{l}\text { Capacidade de satisfazer as } \\
\text { necessidades presentes humanas com } \\
\text { intuito de não } r \text { haver } \\
\text { comprometimento das gerações } \\
\text { futuras, considerando o equilíbrio } \\
\text { econômico, ambiental e social (Wced, } \\
\text { 1987) }\end{array}$ & $\begin{array}{l}\text {-Conservação ambiental-relacionados à proteção da flora e fauna } \\
\text { definidos no UTZ Certified } \\
\text {-Conservação ambiental relacionados ao uso de recursos e tratamento } \\
\text { de resíduos definidos no UTZ Certified } \\
\text {-Regulamentação trabalhista (direito dos trabalhadores) definidos no } \\
\text { UTZ Certified } \\
\text {-Saúde e segurança do trabalhador no UTZ Certified }\end{array}$ \\
\hline
\end{tabular}

Figura 2: Domínio dos construtos e indicadores de "Maturidade"

Fonte: Barra (2016, p. 81)

A figura 3 apresenta os construtos e os indicadores das variáveis latentes "Desempenho". Os itens de mensuração da variável latente "Desempenho" foram definidos a partir das perspectivas mercadológicas e financeiras do BSC. Estas perspectivas foram escolhidas em razão dos objetivos deste trabalho de pesquisa. Vale ressaltar que estas perspectivas representam as principais demandas para a escolha da certificação no mercado de cafés especiais. Os escores de "Desempenho" foram categorizados em cinco níveis: D1, D2, D3, D4, D5. A escolha de cada indicador foi validada por especialistas.

\begin{tabular}{|c|c|c|}
\hline $\begin{array}{l}\text { Variável } \\
\text { Latente }\end{array}$ & $\begin{array}{l}\text { Construto de } \\
\text { primeira ordem }\end{array}$ & Indicadores \\
\hline & 1.Financeiro & $\begin{array}{l}\text { - Aumento do faturamento nos últimos três anos } \\
\text { - Redução de custos nos últimos três anos } \\
\text { - Aumento do retorno sobre o capital investido nos últimos três anos } \\
\text { - Aumento da lucratividade nos últimos três anos }\end{array}$ \\
\hline $\begin{array}{l}\text { Desempe } \\
\text { nho }\end{array}$ & 2.Mercadológico & $\begin{array}{l}\text { - Obtenção de prêmio na venda do café nos últimos três anos } \\
\text { - Aumento do volume de café vendido nos últimos três anos } \\
\text { - Aumento do volume de café especial vendido nos últimos três anos } \\
\text { - Atração de novos clientes nos últimos três anos }\end{array}$ \\
\hline
\end{tabular}

Figura 3: Itens de mensuração da variável latente "Desempenho".

Fonte: Barra (2016, p. 82)

Para definição do nível de maturidade das firmas, foi desenvolvido um método para identificação de pontos-chave de transição (turning points). Os construtos são mensurados por meio do somatório dos seus respectivos indicadores, utilizando a medida estatística da mediana como ponto-chave de transição. Logo, a firma que apresentar um escore abaixo ou igual à mediana entre dois níveis na escala de maturidade será classificada no estágio inferior de maturidade destes níveis. O escore de cada firma é calculado pelo somatório dos escores obtidos dos cinco indicadores dos seis construtos ponderados pelos níveis de maturidade - Adhoc-1, Iniciado-2, Definido-3, Estruturado-4, Otimizado-5 (Figura 4). O escore de desempenho de cada firma é calculado pelo somatório dos escores obtidos dos quatro indicadores dos dois construtos ponderados pelo peso da escala de desempenho - 1, 2, 3, 4, 5 (Figura 5).

\begin{tabular}{|l|l|l|}
\hline $\begin{array}{c}\text { Nível de } \\
\text { maturidade }\end{array}$ & \multicolumn{1}{|c|}{ Escores Máximos do Modelo de Maturidade de Processos } & Ponto-chave de Transição \\
\hline Adhoc & 6 construtos x 5 indicadores x 1 ponto $=$ até 30 pontos & $<45$ \\
\hline Iniciado & 6 construtos x 5 indicadores x 2 pontos $=$ até 60 pontos & $>45<75$ \\
\hline Definido & 6 construtos x 5 indicadores x 3 pontos $=$ até 90 pontos & $>75<105$ \\
\hline Estruturado & 6 construtos x 5 indicadores x 4 pontos $=$ até 120 pontos & $>105<135$ \\
\hline Otimizado & 6 construtos x 5 indicadores x 5 pontos = até 150 pontos & $>135$ \\
\hline
\end{tabular}

Figura 4 - Ponto-chave de transição do modelo de maturidade Mmsag (Maturidade)

Fonte: Barra (2016, p. 84) 


\begin{tabular}{|c|l|l|}
\hline $\begin{array}{c}\text { Nível de } \\
\text { Desempen } \\
\text { ho }\end{array}$ & \multicolumn{1}{|c|}{ Escores máximos do modelo de maturidade de processos } & Ponto-chave de Transição \\
\hline 1 & 2 construtos x 4 indicadores x 1 ponto $=$ até 8 pontos & $<12$ \\
\hline 2 & 2 construtos $\mathrm{x} 4$ indicadores $\mathrm{x} 2$ pontos $=$ até 16 pontos & $>12<20$ \\
\hline 3 & 2 construtos $\mathrm{x} 4$ indicadores $\mathrm{x} 3$ pontos $=$ até 24 pontos & $>20<28$ \\
\hline 4 & 2 construtos $\mathrm{x} 4$ indicadores $\mathrm{x} 4$ pontos $=$ até 32 pontos & $>28<36$ \\
\hline 5 & 2 construtos $\mathrm{x} 4$ indicadores $\mathrm{x} 5$ pontos $=$ até 40 pontos & $>36$ \\
\hline
\end{tabular}

Figura 5 - Ponto-chave de Transição do Modelo de Maturidade Mmsag (Desempenho)

Fonte: Barra (2016, p. 86)

No nível adhoc, o cenário apresentado caracteriza-se por ser embrionário. Entende-se que já existe um curso básico de melhoria contínua dos processos baseado na certificação. Embora os processos ainda não estejam estruturados, os mesmos apresentam elementos culturais de melhoria contínua. Para Mccormack et al. (2003), a construção de uma base cultural que dê suporte aos métodos, práticas e procedimentos que habilitem o processo de maturidade é fundamental para garantir o processo contínuo de manutenção da consistência da maturidade.

\section{METODOLOGIA}

O processo de pesquisa utilizado neste trabalho foi dividido em duas fases: exploratória e conclusiva. Na fase exploratória, foi possível construir o modelo de maturidade, avaliá-lo, ajustá-lo e validá-lo, por meio das seguintes etapas: definição dos estágios de maturidade do modelo; construção das escalas do modelo; avaliação do modelo por especialistas em processos; avaliação do modelo por especialistas em cafeicultura; entrevistas com membros da Federação de Cafeicultores do Cerrado, validação do modelo com membros desta Federação por meio do grupo focal.

A fase conclusiva possibilitou descrever os níveis de maturidade dos processos das firmas certificadas e os níveis de desempenho dessas firmas. Nessa fase, foram realizadas as seguintes etapas: realização do survey; avaliação da validade e da confiabilidade dos construtos; estatística descritiva; análise de correspondência; avaliação dos processos a partir de sua correlação estatística com o desempenho; teste de hipótese do modelo de análise.

Com relação à estratégia, a pesquisa se classifica em qualitativa-quantitativa, estando dividida em duas fases: qualitativa, com especialistas em processo, em cafeicultura e membros da Federação; e quantitativa, com cafeicultores que obtiveram a certificação UTZ Certified.

Neste trabalho, universo da pesquisa foi definido pelo conjunto de cafeicultores certificados pela UTZ. Desse universo, foram selecionados todos esses cafeicultores não optando por realização de amostragem. A unidade de análise da pesquisa foi formada pelas unidades de negócio das firmas certificada pela UTZ. A unidade de observação foi composta pelos gestores destas firmas. O conjunto de respondentes desta pesquisa foi constituído por profissionais com atuação gerencial dessas firmas.

O início da fase exploratória foi realizado no período compreendido entre 2013 e 2015 com intuito de construção do modelo de maturidade. Nesse período, a definição dos estágios de maturidade do modelo e a construção das escalas foram realizadas por meio de uma intensa pesquisa bibliográfica sobre maturidade de processos e modelos de maturidade de processos.

Após a definição dos estágios de maturidade do modelo e a construção das escalas durante o ano de 2014, o modelo de maturidade e o questionário foram avaliados durante os oito primeiros meses de 2015 por uma equipe de três especialistas em gestão de processos e três especialistas em cafeicultura.

Após essa fase, o modelo de maturidade e o questionário foram apresentados a dois integrantes da federação. Posteriormente, o modelo de maturidade e o questionário também foram apresentados ao entrevistado 3 da federação. Em seguida, foi realizada uma seção de grupo focal,

Revista de Gestão Social e Ambiental - RGSA, São Paulo, v. 12, n. 1, p. 89-107, jan./abr. 2018. 
com três produtores e um agrônomo ligados a Federação. Nesta etapa, o modelo de maturidade foi validado, onde foram avaliadas as escalas.

$\mathrm{Na}$ fase conclusiva, foi realizado um survey com o intuito de teste e validação da hipótese do estudo, por meio de análises estatística descritiva e análise de correspondência. Os dados foram obtidos por meio de questionários estruturados, os quais foram enviados pelo correio tradicional e pelo correio eletrônico aos respondentes. A pesquisa compreendeu um universo de 203 produtores. Nessa fase, optou-se pelo censo, em razão do tamanho do universo da pesquisa, composto de 203 produtores. Desse total, o número de cafeicultores que atendeu ao pedido de participação na pesquisa chegou a 55 respondentes.

Para garantir a validade do questionário foram utilizadas técnicas do tipo pré-teste e teste com especialistas. O pré-teste foi realizado com três cafeicultores de forma presencial. Já os testes com especialistas, foram realizados com três professores. $\mathrm{Na}$ fase quantitativa, os dados coletados foram tratados por técnicas estatísticas descritivas e multivariadas. Com o intuito de facilitar o tratamento e a análise dos dados foi utilizado o software Statistical Package for Social Sciences (SPSS) versão 20.0 .

\section{RESULTADOS}

A tabela 1 apresenta a tabulação cruzada entre "Maturidade" e "Tempo de Certificação". Pelos resultados da pesquisa, no nível de maturidade "Otimizado" predominaram as firmas certificadas há mais de 7 anos (54,5\%). Na constituição do nível de maturidade "Estruturado", predominaram as firmas certificadas entre 3 e 4 anos $(47,1 \%)$, seguidas pelas firmas certificadas há mais de 7 anos (33,3\%). No que se refere ao nível de maturidade "Definido", predominaram as firmas certificadas há menos de dois anos $(50 \%)$.

Tabela 1: Tabulação cruzada entre "Maturidade" e "Tempo de Certificação"

\begin{tabular}{|c|c|c|c|c|c|c|}
\hline & \multicolumn{5}{|c|}{ Tempo de certificação } & \multirow[b]{2}{*}{ Total } \\
\hline $\begin{array}{l}\text { Nível de } \\
\text { Maturid } \\
\text { ade }\end{array}$ & $\begin{array}{l}\text { (1) Não } \\
\text { certificado }\end{array}$ & $\begin{array}{l}\text { (2) Menos } \\
\text { de } 2 \text { anos }\end{array}$ & $\begin{array}{c}\text { (3) } 3 \text { e } 4 \\
\text { anos }\end{array}$ & (4) 5 a 6 anos & (5) Mais de 7 anos & \\
\hline $\begin{array}{c}\text { Adhoc } \\
1\end{array}$ & - & - & - & - & - & - \\
\hline $\begin{array}{c}\text { Iniciado } \\
2 \\
\end{array}$ & - & - & - & - & - & - \\
\hline $\begin{array}{c}\text { Definido } \\
3\end{array}$ & - & $\begin{array}{r}2 \\
50,0 \% \\
40,0 \%\end{array}$ & $\begin{array}{r}1 \\
25,0 \% \\
5,9 \%\end{array}$ & $\begin{array}{r}0 \\
0 \% \\
0 \%\end{array}$ & $\begin{array}{r}1 \\
25,0 \% \\
4,0 \%\end{array}$ & $\begin{array}{r}4 \\
100 \% \\
7,3 \%\end{array}$ \\
\hline $\begin{array}{l}\text { Estrutur } \\
\text { ado } \\
\qquad 4\end{array}$ & - & $\begin{array}{r}1 \\
5,6 \% \\
20,0 \%\end{array}$ & $\begin{array}{r}8 \\
44,4 \% \\
47,1 \%\end{array}$ & $\begin{array}{r}3 \\
16,7 \% \\
37,5 \%\end{array}$ & $\begin{array}{r}6 \\
33,3 \% \\
24,0 \%\end{array}$ & $\begin{array}{r}18 \\
100 \% \\
32,7 \%\end{array}$ \\
\hline $\begin{array}{l}\text { Otimiza } \\
\text { do } \\
5\end{array}$ & - & $\begin{array}{r}2 \\
6,1 \% \\
40,0 \%\end{array}$ & $\begin{array}{r}8 \\
24,2 \% \\
47,1 \%\end{array}$ & $\begin{array}{r}5 \\
15,2 \% \\
62,5 \%\end{array}$ & $\begin{array}{r}18 \\
54,5 \% \\
72,0 \%\end{array}$ & $\begin{array}{r}33 \\
100,0 \% \\
60,0 \%\end{array}$ \\
\hline Total & - & $\begin{array}{r}5 \\
9,1 \% \\
100,0 \%\end{array}$ & $\begin{array}{r}17 \\
30,9 \% \\
100,0 \%\end{array}$ & $\begin{array}{r}8 \\
14,5 \% \\
100,0 \%\end{array}$ & $\begin{array}{r}25 \\
45,5 \% \\
100,0 \%\end{array}$ & $\begin{array}{r}55 \\
100 \% \\
100 \%\end{array}$ \\
\hline
\end{tabular}

Fonte: Dados da pesquisa

A partir dos dados da tabela 1, constata-se que as empresas com maior tempo de certificação obtiveram maior nível de maturidade. A Tabela 2 apresenta a estatística descritiva para os seis construtos formadores do construto "Maturidade". Pela análise das médias da tabela 2, constatam-se níveis próximos de maturidade entre os construtos formadores do construto "Maturidade", exceto o 
construto "Medição de Processos". Na análise da média, desvio-padrão, mediana, mínimo e quartil percebe-se que o construto "Medição de Processos" apresenta valores abaixo dos demais construtos.

Tabela 2: Estatística descritiva para os construtos formadores de "Maturidade"

\begin{tabular}{|c|c|c|c|c|c|c|c|}
\hline & $\begin{array}{c}\text { Documentação } \\
\text { de processos }\end{array}$ & $\begin{array}{l}\text { Medição de } \\
\text { processos }\end{array}$ & $\begin{array}{c}\text { Rastreabilidade } \\
\text { de processos }\end{array}$ & $\begin{array}{l}\text { BPA de } \\
\text { Lavoura }\end{array}$ & $\begin{array}{c}\text { BPA de } \\
\text { Processamento }\end{array}$ & $\begin{array}{l}\text { Sustentabilidade } \\
\text { de processos }\end{array}$ \\
\hline \multicolumn{2}{|c|}{ Média } & 21,89 & 20,34 & 23,38 & 22,65 & 22,96 & 22,65 \\
\hline \multicolumn{2}{|c|}{$\begin{array}{l}\text { Desvio- } \\
\text { Padrão }\end{array}$} & 3,46 & 4,60 & 2,67 & 2,96 & 2,64 & 3,26 \\
\hline \multicolumn{2}{|c|}{ Mediana } & 23 & 21 & 25 & 24 & 25 & 24 \\
\hline \multicolumn{2}{|c|}{ Mínimo } & 8 & 8 & 14 & 12 & 14 & 8 \\
\hline \multicolumn{2}{|c|}{ Máximo } & 25 & 25 & 25 & 25 & 25 & 25 \\
\hline \multirow{3}{*}{$\begin{array}{l}\text { Quar } \\
\text { til }\end{array}$} & 25 & 20 & 18 & 22 & 21 & 21 & 21 \\
\hline & 50 & 23 & 21 & 25 & 24 & 25 & 24 \\
\hline & 75 & 25 & 24 & 25 & 25 & 25 & 25 \\
\hline
\end{tabular}

Fonte: Dados da pesquisa

A figura 6 apresenta os níveis de maturidade dos processos das firmas certificadas. Pode-se inferir que as firmas pesquisadas apresentam nível satisfatório de maturidade em seus processos. Ao analisar a diferença entre as médias dos escores dos construtos, constata-se que o escore médio do construto "Medição de Processos" ficou abaixo dos escores médios dos demais construtos.

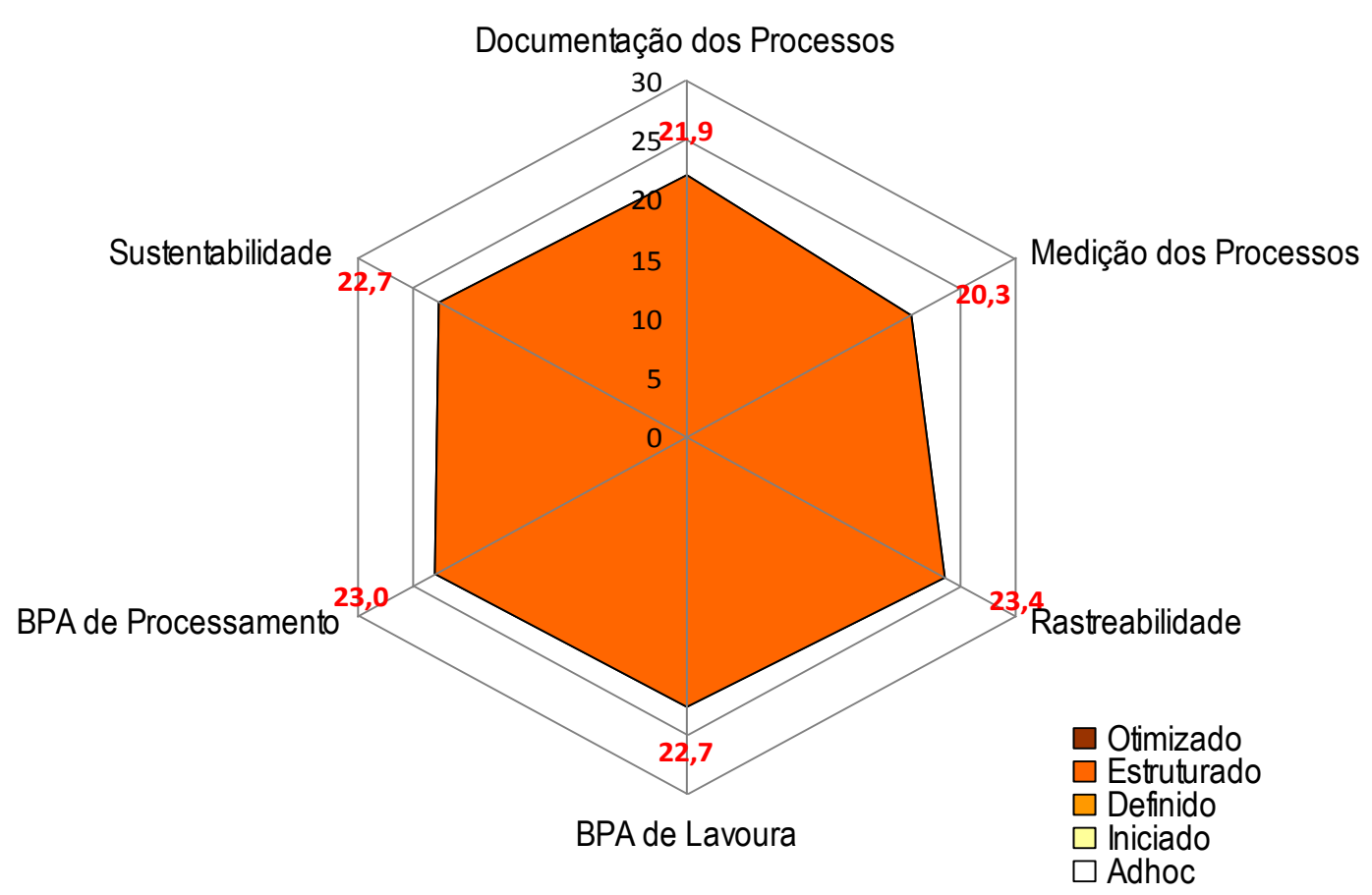

Figura 6: Níveis médios de maturidade dos processos das firmas certificadas

Fonte: Dados da pesquisa

\subsubsection{Níveis de desempenho}

Os construtos de "Desempenho" foram mensurados por meio do somatório dos seus respectivos indicadores, utilizando a medida estatística da mediana como ponto-chave de transição. A Tabela 3 apresenta a estatística descritiva para os dois construtos formadores do construto "Desempenho". Na análise da média, desvio-padrão, mediana, mínimo e quartil percebe-se que os construtos "Desempenho Mercadológico" e "Desempenho Financeiro" apresentam valores homogêneos. 
Tabela 3: Estatística descritiva para os construtos formadores de "Desempenho"

\begin{tabular}{|c|c|c|c|}
\hline \multicolumn{2}{|c|}{ Desempenho } & Mercadológico & Financeiro \\
\hline \multicolumn{2}{|l|}{ Média } & 14,32 & 14,40 \\
\hline \multicolumn{2}{|c|}{ Desvio-padrão } & 3,99 & 3,92 \\
\hline \multicolumn{2}{|c|}{ Mediana } & 15 & 15 \\
\hline \multicolumn{2}{|l|}{ Mínimo } & 4 & 6 \\
\hline \multicolumn{2}{|l|}{ Máximo } & 20 & 20 \\
\hline \multirow{3}{*}{ Quartil } & 25 & 12 & 12 \\
\hline & 50 & 15 & 15 \\
\hline & 75 & 17 & 17 \\
\hline
\end{tabular}

Fonte: Dados da pesquisa

\subsection{Impacto da maturidade no desempenho}

Neste estudo, as variáveis "Maturidade" e "Desempenho" necessitaram ser categorizadas previamente para que a técnica de análise de correspondência fosse aplicável. Sendo assim, tanto no caso da variável "Maturidade" como também no caso da variável "Desempenho", o critério de categorização adotado foi o ponto-chave de transição definido neste trabalho.

A análise da relação entre as variáveis "Maturidade" e "Desempenho" foi composta por cinco etapas. Na primeira etapa, a tabela de contingência foi apresentada com intuito de compreender como cada nível de "Maturidade" contribui para a constituição das classes da variável "Desempenho". Na segunda etapa desse método, foi realizado o teste qui-quadrado de Pearson, de modo a verificar a existência de associação entre as categorias das variáveis. Essa etapa foi complementada pela análise de resíduos padronizados ajustados que sinaliza, por célula, a probabilidade de excesso ou falta de ocorrências, que constitui a terceira etapa. A quarta etapa desse método refere-se aos procedimentos gráficos da análise de correspondência. Nessa etapa, foi realizada a análise das relações gráficas estabelecidas pelo procedimento análise de correspondência (Anacor) do software Spss.

Os cinco níveis da variável "Maturidade" e os cinco níveis da variável "Desempenho" determinam 25 combinações possíveis. A tabela 4 apresenta a tabulação cruzada entre "Maturidade" e "Desempenho". Destaca-se, inicialmente, que 60\% das firmas pesquisadas neste estudo obtiveram o nível de maturidade "Otimizado" e que o nível de desempenho 4 responde por $43,6 \%$ do total de organizações.

Tabela 4 - Tabulação cruzada entre "Maturidade" e "Desempenho"

\begin{tabular}{|c|c|c|c|c|c|c|}
\hline & \multicolumn{5}{|c|}{ Nível de Desempenho } & \multirow[b]{2}{*}{ Total } \\
\hline $\begin{array}{c}\text { Maturidad } \\
\mathrm{e}\end{array}$ & D1 & D2 & D3 & D4 & D5 & \\
\hline $\begin{array}{c}\text { Adhoc } \\
1 \\
\end{array}$ & - & - & - & - & - & - \\
\hline $\begin{array}{c}\text { Iniciado } \\
2 \\
\end{array}$ & - & - & - & - & - & - \\
\hline $\begin{array}{c}\text { Definido } \\
3 \\
\end{array}$ & $\begin{array}{r}2 \\
50 \% \\
100 \% \\
\end{array}$ & $\begin{array}{r}2 \\
50 \% \\
50 \% \\
\end{array}$ & - & - & - & $\begin{array}{r}4 \\
100 \% \\
7,27 \% \\
\end{array}$ \\
\hline $\begin{array}{c}\text { Estruturad } \\
\text { o } \\
4 \\
\end{array}$ & - & $\begin{array}{r}2 \\
11,1 \% \\
50 \%\end{array}$ & $\begin{array}{r}9 \\
50 \% \\
56,3 \%\end{array}$ & $\begin{array}{r}5 \\
27,8 \% \\
20,8 \%\end{array}$ & $\begin{array}{r}2 \\
11,1 \% \\
22,2 \%\end{array}$ & $\begin{array}{r}18 \\
100 \% \\
32,73 \%\end{array}$ \\
\hline $\begin{array}{c}\text { Otimizado } \\
5\end{array}$ & - & - & $\begin{array}{r}7 \\
21,2 \% \\
43,8 \% \\
\end{array}$ & $\begin{array}{r}19 \\
57,6 \% \\
79,2 \% \\
\end{array}$ & $\begin{array}{r}7 \\
21,2 \% \\
77,8 \\
\end{array}$ & $\begin{array}{r}33 \\
100 \% \\
60 \% \\
\end{array}$ \\
\hline
\end{tabular}

Revista de Gestão Social e Ambiental - RGSA, São Paulo, v. 12, n. 1, p. 89-107, jan./abr. 2018. 


\begin{tabular}{r|r|r|r|r|r|r}
\hline \multirow{3}{*}{ Total } & 2 & 4 & 16 & 24 & 9 & 55 \\
& $3,64 \%$ & $7,27 \%$ & $29,1 \%$ & $43,6 \%$ & $16,4 \%$ & $100 \%$ \\
& $100 \%$ & $100 \%$ & $100 \%$ & $100 \%$ & $100 \%$ & $100 \%$ \\
\hline
\end{tabular}

Fonte: Dados da pesquisa

Pelos resultados da tabela 4, integraram o nível de desempenho "D5", em ordem decrescente, as firmas classificadas no padrão de maturidade "Otimizado" $(77,8 \%)$ e as firmas classificadas no padrão de maturidade "Estruturado" (22,2\%). Na constituição do nível de desempenho "D4", também predominaram as firmas classificadas no padrão de maturidade "Otimizado" (79,2\%) seguidas pelas firmas classificadas no padrão de maturidade "Estruturado" $(20,8 \%)$.

No que se refere ao nível de desempenho "D3", ele foi composto por firmas classificadas no padrão de maturidade "Estruturado" $(56,3 \%)$ e as firmas classificadas no padrão de maturidade "Otimizado" (43,8\%). O nível de desempenho "D2" foi constituído por firmas classificadas no padrão de maturidade "Definido" (50\%) e as firmas classificadas no padrão de maturidade "Estruturado" (50\%). Por fim, o nível de desempenho "D1" foi constituído apenas por firmas classificadas no padrão de maturidade "Definido" (100\%).

A figura 7 é composto por duas dimensões que estabelecem relações entre as variáveis "Maturidade" e "Desempenho" evidenciando a natureza da associação entre suas categorias. Para tanto, fundamenta-se em um método particular de normalização denominado simétrico ou canônico. Para cada dimensão, as coordenadas de linha corresponderão à média ponderada das colunas divididas pelo valor singular correspondente (eigenvalue). As coordenadas de coluna serão determinadas de modo análogo. A análise conjunta das categorias das variáveis "Maturidade" e "Desempenho" apresentadas na figura 7 demonstra a associação do nível de maturidade "Otimizado-5" com o nível de desempenho "D5" e com o nível de desempenho "D4". Já o nível de maturidade "Estruturado-4) demonstra uma associação com o nível de desempenho "D3". Já o nível de maturidade "Definido-3" demonstra uma associação com o nível de desempenho "D1". Esses resultados indicam que há uma relação neste estudo entre maior nível de maturidade com maior nível de desempenho. 


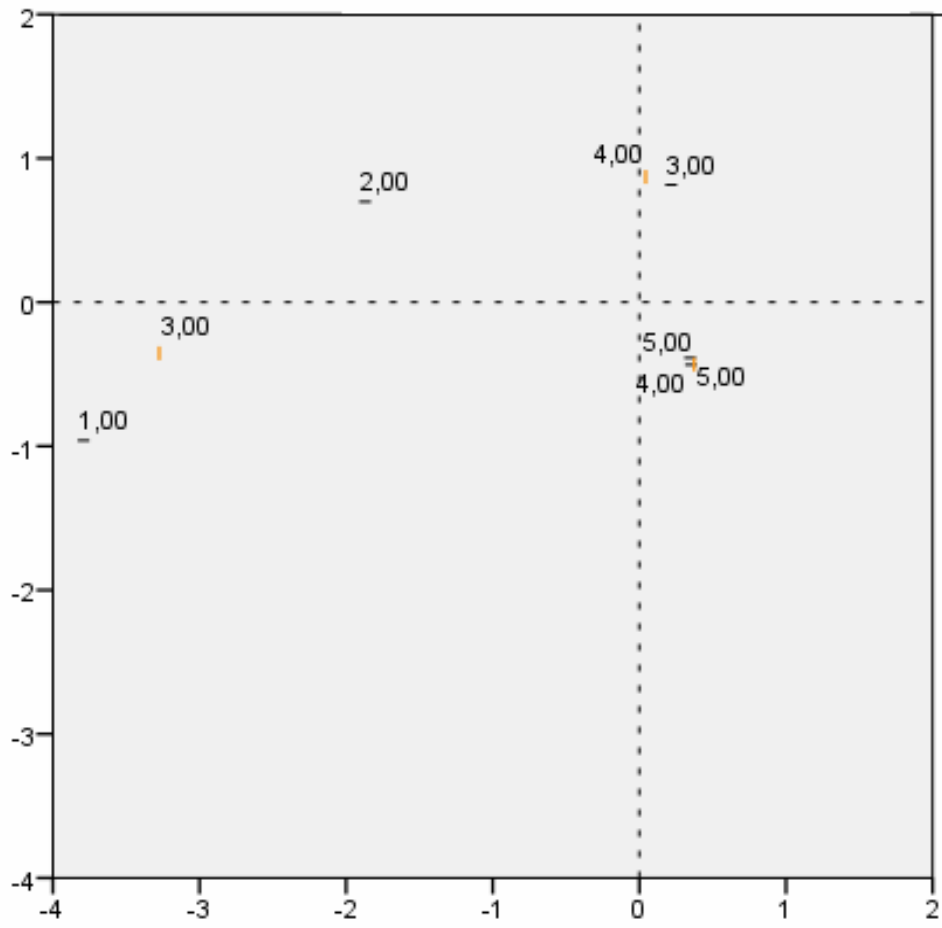

- Desempenho

Maturidade

Figura 7- Gráfico de duas dimensões "Maturidade" e "Desempenho"

Fonte: Dados da pesquisa

\section{DISCUSSÃO}

Os resultados da pesquisa indicam que as empresas investigadas apresentam processos homogêneos em três níveis de Maturidade de Processos, determinados pelos pontos-chaves de transição do construto "Maturidade". O maior grupo foi composto por empresas classificadas no nível de Maturidade de Processos denominado "Otimizado", compreendido pelas empresas com pontuação superior a 135 pontos. Por sua vez, o segundo maior grupo foi composto por empresas classificadas no nível de Maturidade de Processos denominado "Estruturado", compreendido pelas empresas com pontuação entre 105 pontos e 135 pontos. Por fim, o menor grupo definido pelo resultado desta pesquisa foi composto por empresas classificadas no nível de Maturidade de Processos "Definido", com pontuação compreendida entre 60 pontos e 105 pontos. Conclui-se assim, que a maioria das firmas certificadas que compôs a amostra da pesquisa ficou classificada nos dois primeiros níveis de Maturidade, caracterizando assim um elevado nível de maturidade dessas firmas.

Os resultados da pesquisa indicam que as empresas apresentam processos homogêneos nos quatro níveis de desempenho, determinados pelos pontos-chaves de transição do construto "Desempenho". Pelo resultado desta pesquisa, o maior grupo foi composto por empresas classificadas no nível de Desempenho denominado "D4", com pontuação compreendida entre 28 pontos e 36 pontos. Já o segundo maior grupo, foi composto por empresas classificadas no nível de Desempenho denominado "D3", em que o escore de maturidade ficou compreendido entre 20 pontos e 28 pontos. Por sua vez, o terceiro maior grupo foi composto por empresas classificadas no nível de Desempenho denominado "D5", compreendido pelas empresas com pontuação superior a 
36 pontos. Finalmente, o menor grupo foi composto por empresas classificadas no nível de Desempenho "D2", com pontuação compreendida entre 12 pontos e 20 pontos.

De acordo com a análise da tabulação cruzada entre "Maturidade" e "Desempenho", identificou-se que, de uma forma geral, as firmas com os maiores níveis de maturidade apresentaram maior nível de desempenho. Segundo os dados, integraram o nível de desempenho "D5" e "D4" as firmas classificadas no nível de maturidade "Otimizado" e no nível de maturidade "Estruturado". Em um nível intermediário, denominado "D3”, foi composto por firmas classificadas no nível de maturidade "Estruturado". Por fim, nos níveis de desempenho mais inferiores, foram agrupadas as firmas de menores níveis de maturidade.

Além da diferença de pontuação entre os três grupos de níveis de maturidade, houve também uma significativa diferença dos três grupos com relação ao desempenho. Esta diferença foi evidenciada já na análise da estatística descritiva, indicando a possibilidade de confirmação da hipótese da pesquisa, de uma associação positiva e significativa entre níveis de maturidade dos processos das firmas certificadas no SAG do café e nível de desempenho dessas organizações.

Para se testar essa hipótese de pesquisa, foi realizada a análise de correspondência. Pela análise de correspondência, verificou-se que, ao realizar a análise conjunta das categorias das variáveis "Maturidade" e "Desempenho", foi demonstrada uma associação do nível de maturidade "Otimizado" com o nível de desempenho "D5" e com o nível de desempenho "D4". Já o nível de Maturidade "Estruturado" demonstra uma associação com o nível de desempenho "D3". Por sua vez, o nível de maturidade "Definido", uma associação com o nível de desempenho "D1". Esses resultados demonstram que há uma relação neste estudo entre maior nível de maturidade com maior nível de desempenho. Foi possível compreender que a variável "Maturidade" influencia a variável "Desempenho". Logo, é possível afirmar que a hipótese deste trabalho foi confirmada, indicando que quanto maior o grau de maturidade, maior é o desempenho.

Neste estudo, buscou-se também verificar possíveis relações, encontradas nos dados da pesquisa, que pudessem enriquecer a discussão sobre esta questão, merecendo destaque a relação "Maturidade" e "Tempo de Certificação". De acordo com a análise dos resultados da tabulação cruzada entre "Maturidade" e "Tempo de Certificação", identificou-se que as firmas com os maiores tempos de certificação apresentaram também maiores níveis de maturidade. Identificou-se que, no nível de maturidade "Otimizado", predominaram as firmas certificadas há mais de 7 anos. $\mathrm{Na}$ constituição do nível de maturidade "Estruturado", predominaram as firmas certificadas entre 3 e $4 \operatorname{anos}$ e as firmas certificadas há mais de 7 anos. No nível de maturidade "Definido", predominaram as firmas certificadas há menos de 2 anos.

O resultado sobre a relação de maturidade e tempo de certificação deste estudo, conquanto seja apenas sobre um grupo de empresas certificadas, vem trazer uma contribuição teórica para a crença de que as empresas já certificadas tendem a se tornar mais maduras com o tempo, pela maturação dos seus processos.

$\mathrm{Na}$ análise da média dos escores dos seis construtos de "Maturidade", foi possível verificar que os valores ficaram próximos entre si. Ao analisar a diferença entre as médias dos escores e outras medidas estatísticas de centralidade e de dispersão, constata-se que o escore médio do construto "Medição de Processos" apresentou resultados abaixo dos demais construtos. Esse resultado pode indicar a necessidade de maior evolução com relação às práticas de mensuração de processos nesse conjunto de empresas.

O código de conduta da UTZ é um padrão que possibilita aos cafeicultores aliar a melhoria da qualidade dos cafés com a incorporação de práticas de gestão socioambientais. $\mathrm{O}$ código de conduta da UTZ nivela os cafeicultores com relação a práticas produtivas compatíveis com as exigências do mercado comprador de cafés sustentáveis, principalmente com relação às demandas por qualidade, segurança alimentar, responsabilidade social, proteção ambiental e rastreabilidade.

De fato, a UTZ tem um padrão de conduta que atende a diversos requisitos exigidos por normas internacionais. O código de conduta da UTZ apresenta uma metodologia que abrange as questões de qualidade, ambientais e sociais. A marca UTZ é o mecanismo sinalizador de qualidade 
dessa entidade que mais se destaca no mercado de cafés sustentáveis. Já a rastreabilidade da UTZ pode vir a ser uma forma de coordenação eficiente do sistema produtivo, pois a sua sistemática permite que o café seja acompanhado no portal da UTZ.

A certificação UTZ foi uma iniciativa importante para o desenvolvimento de canais de distribuição no mercado de cafés sustentáveis. Tal fato ocorre em razão de os cafés sustentáveis caracterizarem-se por apresentar atributos tangíveis e intangíveis que, em muitas situações, são difíceis de serem visualizados pelos consumidores no momento da compra.

De acordo com a visão do entrevistado 4, pode-se observar que uma das vantagens da certificação está relacionada a uma maior organização da fazenda e melhoria da gestão. Esse cafeicultor comentou que a base para implantação da UTZ foi o investimento em base cultural.

Em resumo, este trabalho traz uma concepção original aos estudos sobre maturidade de processos ao inserir a certificação de melhores práticas como elemento norteador e que viabiliza a condução da trajetória da maturidade das firmas. Ademais, por ter sido desenvolvido com o foco em um SAG no país, há contribuições relevantes que poderão ser projetadas e futuramente avaliadas em SAGs de outros setores que não o cafeeiro.

\section{CONSIDERAÇÕES FINAIS}

Os resultados da pesquisa evidenciaram que as empresas com maior nível de maturidade de processos certificados tendem a apresentar um melhor desempenho em áreas críticas do desempenho financeiro e mercadológico. Os resultados da pesquisa indicam que, além disso, as firmas com os maiores tempos de certificação apresentaram os maiores níveis de maturidade. Em outros termos, foi percebido que níveis superiores de maturidade de processos são estabelecidos por um processo evolutivo de difusão de melhores práticas, fruto da certificação, e estão relacionados ao nível de desempenho das firmas certificadas.

Nesse sentido, os resultados da pesquisa corroboram a concepção teórica da existência de uma correlação positiva e relevante entre níveis de maturidade e o desempenho das firmas. Além disso, os resultados confirmam que níveis superiores de maturidade são estabelecidos por um processo evolutivo de difusão de melhores práticas, corroborando estudos anteriores (Lockamy e MCCormarck, 2004; Oliveira, 2009).

Esses resultados, em seu conjunto, corroboram o papel da certificação na melhoria da gestão das firmas certificadas no SAG de café. Particularmente, os resultados indicaram que a certificação UTZ é exemplo de um instrumento de difusão e institucionalização de melhores práticas produtivas no SAG de café na perspectiva da sustentabilidade.

De fato, os projetos de certificação desenvolvidos no SAG de café no Brasil deflagraram uma substancial melhoria dos processos de organizações do setor. Nesse contexto, o código de conduta da UTZ passou a desempenhar um conjunto de atividades voltadas à melhoria dos processos de produção e comercialização e integração no SAG, impactando na coordenação desses sistemas produtivos.

A UTZ destaca-se no mercado de cafés sustentáveis por ser um agente de suporte institucional e que facilitou o processo de empreendimento no mercado de cafés sustentáveis por meio do seu sistema de certificação. Essa organização criou um conjunto de ações voltadas para facilitar o processo de produção e comercialização dos cafeicultores em uma nova perspectiva, baseada na concepção de sustentabilidade. Destaca-se, então, a importante participação da certificação UTZ como um condutor basilar para as etapas evolutivas da maturidade de processos dentro da concepção da sustentabilidade.

A principal contribuição científica deste trabalho foi a validação do modelo de maturidade para empresas certificadas em SAGs. Tal desenvolvimento abre oportunidades importantes não somente para o adensamento do próprio percurso teórico relativo ao desenvolvimento de modelos de maturidade, como também para o planejamento de melhorias do desempenho de empresas brasileiras desse setor. 
Vale destacar que o Mmsag apresenta vantagens em relação a outros modelos de maturidade, tal como o Pemm de Hammer (1997), por vincular diretamente os níveis de maturidade aos resultados de desempenho de processos. O modelo Mmsag permite investigar em uma perspectiva temporal as relações entre níveis de maturidade e o desempenho dos processos das firmas.

Ao confrontar as proposições teóricas com a realidade empírica, verifica-se que este estudo é uma evidência da importância de processos certificados para o desempenho empresarial em uma concepção da sustentabilidade. Cabe reforçar, portanto, a importância da certificação para a sustentabilidade. Entretanto, acredita-se que estudos continuados de outras realidades são necessários para a compreensão mais adequada dessa problemática.

Este trabalho apresentou uma contribuição relevante para o contexto de negócios agroindustriais ao adaptar o conceito de modelos de maturidade de processos já incorporado na prática de outros sistemas produtivos aos sistemas agroindustriais em uma perspectiva sistêmica, como visto nos capítulos iniciais deste trabalho.

Embora se ressalte a relevância dos construtos propostos, tanto em relação às práticas e exigências empresariais contemporâneas quanto também em relação à perspectiva teórica sobre o tema, há que se destacar as limitações características deste estudo. A complementação deste trabalho é necessária por meio de estudos conclusivos, do tipo longitudinais, para verificar a evolução das empresas no tempo.

Ademais, é importante assinalar que a proposta de aplicação empresarial do Mmsag está centrada no diagnóstico dos níveis de maturidade de processos. Isto é, a proposta de aplicação não foi definida propriamente na prescrição de ações ou práticas a serem adotadas para que as firmas possam superar um determinado nível de maturidade em direção a um nível superior por meio de um roadmap (guia).

Neste estudo, foi escolhida a perspectiva interna, conquanto, o Mmsag tenha sido desenvolvido com a possibilidade de aplicação em três níveis de análise: interna (processos intraorganizacionais); díade (processos interorganizacionais); sistêmica (processos de toda uma cadeia produtiva). Essa escolha foi determinada em razão dos cafeicultores ainda estarem centrados nos processos de produção. Todavia, vale ressaltar que alguns desses produtores já estão trabalhando em uma perspectiva de integração vertical para frente, como já identificado, nesta pesquisa, por produtores, tais como a comercialização de café torrado e moído.

Assim sendo, é interessante que o modelo seja aplicado em pesquisas futuras nas outras duas perspectivas. Há a expectativa de que a aplicação do Mmsag, tanto na perspectiva da díade, como também na perspectiva externa, proverá um adensamento do próprio percurso teórico relativo ao desenvolvimento de modelos de maturidade em SAGs.

Conquanto, os resultados deste estudo estejam ancorados em evidências de dados qualitativos e quantitativos, o que proporcionou amplitude e profundidade à pesquisa, acredita-se que estudos futuros poderiam vir a enfatizar abordagens mais qualitativas sobre o objeto, aportando informações valiosas sobre a problemática abordada neste trabalho.

Embora seja esta uma proposta de pesquisa de caráter eminentemente científico, a natureza do problema de pesquisa define implicações práticas relevantes para as empresas. Ao aplicar o método do Mmsag proposto é possível a difusão dos resultados e o aporte de recomendações gerenciais.

A aplicação do Mmsag em futuras pesquisas aplicadas poderá gerar resultados práticos para as organizações que poderiam vir a receber um relatório individual, para fins de benchmarking e um relatório global, com os resultados descritivos do levantamento. Cada firma poderia vir a receber um escore obtido para cada indicador do modelo e o comparativo em relação à média das outras firmas da amostra, o que possibilitaria aos gestores reconhecer os pontos críticos que precisam ser melhorados para a evolução da maturidade em um SAG específico.

Por fim, acredita-se que os especialistas, em razão dos pontos críticos demonstrados pelo Mmsag, podem sugerir recomendações para a melhoria dos processos, permitindo a priorização de 
esforços e recursos pela firma. Há necessidade de orientar o processo de implantação das recomendações definidas pelo resultado do Mmsag, bem como é importante realizar o acompanhamento, visando o controle.

\section{NOTA}

${ }^{1}$ Kaplan e Norton (1997) aceitam a utilização do BSC com menos de quatro perspectivas, ou, ainda, com mais de quatro perspectivas.

\section{REFERÊNCIAS}

Barra, G. M. J. (2006). O suporte das associações de interesse privado em canais de distribuição de produtos diferenciados: um estudo de caso no mercado de cafés especiais. 132 p. Dissertação (Mestrado em Administração) - Universidade Federal de Lavras, Lavras.

Barra, G. M. J. (2016). Modelo de maturidade para processos certificados em sistemas agroindustriais. 179 p. Tese (Doutorado em Administração) - Universidade Federal de Minas Gerais, Belo Horizonte.

Bronzo, M. L., Resende, P. T. V., Oliveira, M.P.V., Mccormack, K., Sousa, P.R., Ferreira, R.L. (2013). Improving performance aligning business analytics with process orientation. International Journal of Information Management, 33, 300-307.

Crosby, P. B.L (1979). Quality is free: the art of making quality certain. Nova York: McGraw-Hill Companies.

Dutra, D. M. R. (2009) Ações públicas e privadas na implantação e desenvolvimento da indicação geográfica do café em Minas Gerais: evolução e perspectivas na visão de seus gestores. Dissertação (Mestrado em Administração) - Universidade Federal de Lavras, Lavras.

Hammer, M. (2007) The process audit. Harvard Business Review, Abril, 111-123

Kaplan, R. S., Norton, D. P. A. (1997). A estratégia em ação: balanced scorecard. (4.ed.) Rio de Janeiro: Campus.

Lahti, M.; Shamsuzzoha, A. H. M., Helo, P. (2009). Developing a maturity model for Supply Chain Management. International Journal of Logistics Systems and Management, 5(6), 654-678.

Leme, P. H. M. V. (2015). A construção do mercado de cafés certificados e sustentáveis da UTZ Certified no Brasil: as práticas e os arranjos de mercado. 274 p. Tese (Tese em Administração) - Universidade Federal de Lavras, Lavras.

Lockamy, A., Mccormack, K. (2004). The development of a supply chain management process maturity model using the concepts of business process orientation. Supply Chain Management: An International Journal, 9(4), 272-278.

Mafra, L.A.S. (2008). Indicação geográfica e construção do mercado: a valorização da origem no Cerrado Mineiro. Tese (Doutorado em ciências sociais). Rio de Janeiro: UFRRJ.

Martinez, J. L. T. (2006). Impactos da certificação Utz Kapeh em fazendas de café: estudo de casos enfatizando o sistema de informação. 132 p. Dissertação (Mestrado em Administração) - Universidade Federal de Lavras, Lavras.

Miranda, B. V., Saes, M. S. M. (2012). Coordenação e qualidade no sistema fairtrade: o exemplo do café. Organizações Rurais \& Agroindustriais, Lavras, 14(3), 367-379.

Mccormack, K., Johnson, W., Walker, W. (2003). Supply Chain Networks and Business Process Orientation: Advanced Strategies and Best Pratices. Apics series on resource management. CRC Press LLC. Boca Raton, Florida.

Mccormack, K., Bronzo, M., Oliveira, M. P. V. (2007). Supply chain management maturity and logistics performance. Supply Chain Management: an International Journal (SCMIJ)/Emerald, July, 13, 272 - 282. 
Oliveira, M. P. (2009). Modelo de maturidade de processos em cadeias de suprimentos: precedências e os pontos-chave de transição. Tese (Doutorado em Administração) - Universidade Federal de Minas Gerais, Belo Horizonte.

Oliveira, M. P. V., Mccormack, K., Bronzo, M. L.(2007). An empirical approach for the relationship between logistical performance and logistical process maturity In: Nuran Acur, Nesim, K. Erkip; Evrim Didem Güne (Org) Managing operations in an expanding Europe. Ankara: Editora da Universidade Bilkent.

Oliveira, M.P.V., Bronzo, M., Mccormack, K., (2011). The supply chain process management maturity model -SCPM3. In: Onkal, D. (org) Supply Chain Management: Pathways for Research and Practice, 201218, Agosto.

Palmieri, R. H. (2008). Impactos socioambientais da certificação Rainforest Alliance em fazendas produtoras de café no Brasil. Dissertação (Mestrado em Administração) - Universidade de São Paulo. Faculdade de Economia, Administração e Contabilidade, São Paulo.

Panhuysen, S., Pierrot, J. (2014). Coffee Barometer. The Hague: Tropical Commodity Coalition, 15 p.

Pedini, S. (2011). Fair trade: alternativa ao mercado convencional de café e processos de empoderamento de cafeicultores familiares. Tese (Doutorado em Administração) - Universidade Federal de Lavras.

Pereira, S. P. (2013). Caracterização de propriedades cafeeiras com relação às boas práticas agrícolas: aplicação das análises de cluster e discriminante. 138 p. Tese (Tese em Agronomia) - Universidade Federal de Lavras, Lavras.

Potts, J. et al. (2014). The state of sustainability initiatives review 2014: standards and the green economy. London: International Institute for Sustainable Development, 254 p.

Prado, A. S. (2014). Boas práticas agrícolas e certificação na cafeicultura. 128 p. Dissertação (Mestrado em Administração) - Universidade Federal de Lavras, Lavras.

Rosa, B. T. (2014). Caracterização das "boas práticas agrícolas" e roteiro metodológico para a certificação da cafeicultura familiar no Sul de Minas. 145 p. Dissertação (Mestrado em Administração) Universidade Federal de Lavras, Lavras.

Reinecke, J., Manning, S., Hagen, O. V. (2012). The emergence of a standards market: multiplicity of sustainability standards in the global coffee industry. Organization Studies, Berlin, 33(5/6), 791-814.

Souza, R. P., Guerreiro, R., Oliveira, M. P. V. de. (2015). Relationship between the maturity of supply chain process management and the organisational life cycle. Business Process Management Journal, 21, 466-481.

Trkman, P., Bronzo, M., Oliveira, M. P. V., Mccormack, K. (2011). Business analytics, process maturity and supply chain performance In: 7th International Workshop on Business Process Intelligence (BPI '11).

Trkman, P., Oliveira, M. P. V., Mccormack, K., Bronzo, M. (2012) Business analytics, process maturity and supply chain performance In: Business Process Management: Lecture Notes in Business Information Processing. Berlin: Springer, 111-122.

UTZ Certified. (2015). Código de conduta núcleo. Versão 1.1. Amsterdam.Recuperado em: 1 set.2015, de: <https://utzcertified.org/attachments/article/26584877/PT\%20-\%20Core\%20Code\%20for\%20 Individual\%20Certification\%20v1.1.pdf>.

World Comission on Enviromental and Development - WCED. (1987). Our common future. Oxford: Oxford University Press.

Data da submissão: 22/02/2017

Data de aceite: $30 / 11 / 2017$

Revista de Gestão Social e Ambiental - RGSA, São Paulo, v. 12, n. 1, p. 89-107, jan./abr. 2018. 